УДК 611-012

(C) А. Г. Кварацхелия, Д. А. Соколов, 2018

https://doi.org/10.18499/2225-7357-2018-7-1-53-61

\title{
РЕДКИЙ СЛУЧАЙ МНОЖЕСТВЕННЫХ АНОМАЛИЙ
}

\author{
А. Г. Кварацхелия, Д. А. Соколов \\ ФГБОУ ВО «Воронежский государственный медицинский университет им. Н. Н. Бурденко» \\ Минздрава России, Воронеж, Россия
}

\begin{abstract}
Целью исследование стало описание редкого случая множественных аномалий сердечнососудистой, периферической нервной и половой систем организма человека.

Материал и методы. Препарированию подвергся труп мужчины 52 лет, фиксированный 10\% раствором формалина. В процессе исследования проводились морфометрические измерения анатомических оъектов с использованием штангенциркуля. Из добавочного третьего яичка иссекали фрагмент ткани размером 0.5×0.5×0.5 cм, дополнительно фиксировали в $10 \%$ растворе нейтрального формалина в течение суток, затем проводили по спиртам восходящей концентрации и заливали в парафин. Срезы толщиной 5 мкм окрашивали гематоксилином и эозином.

Результаты. Обнаружена билатеральная аномалия наружной сонной артерии, заключающаяся в дистопии ее ветвей и наличии атипичных добавочных сосудов, кровоснабжающих гортань и трахею. Наблюдали билатеральный вариант топографии подъязычного нерва. Зафиксирована двусторонняя аномалия латерального кожного нерва бедра. Описан случай дистопии добавочного третьего яичка.

Заключение. Обнаруженные множественные варианты аномалий кровеносных сосудов, периферических нервов и внутренних половых органов у одного индивида являются, по-видимому, свидетельством различных нарушений происходивших в эмбриональном периоде. Полученные данные необходимо учитывать в сердечно-сосудистой, неврологической и андрологической практике.

Ключевые слова: вариантная анатомия, множественные аномалии, сонная артерия, подъязчный нерв, латеральный кожный нерв бедра, добавочное яичко, дистопия.
\end{abstract}

(C) A. G. Kvaratskheliya, D. A. Sokolov, 2018

Voronezh N.N. Burdenko State Medical University, Voronezh, Russia

A Rare Case of Multiple Anomalies

The aim of the study was to describe a rare case of multiple anomalies of the cardiovascular, peripheral nervous and reproductive systems of the human body.

Material and methods. A corpse of a man of 52 years old, fixed with a $10 \%$ formalin solution, was dissected. In the course of the study, morphometric measurements of anatomical objects were performed using a caliper. From the additional third testicle, a tissue fragment $0.5 \times 0.5 \times 0.5 \mathrm{~cm}$ in size was excised, additionally fixed in a $10 \%$ neutral formalin solution for 24 hours, then conducted on alcohols of ascending concentration and poured into paraffin. Sections $5 \mu \mathrm{m}$ thick were stained with hematoxylin and eosin.

Results. A bilateral anomaly of the external carotid artery was found, consisting in the dystopia of its branches and the presence of atypical additional vessels, blood supplying the larynx and trachea. A bilateral variant of the sublingual nerve topography was observed. A bilateral anomaly of the lateral cutaneous nerve of the femur was recorded. The case of the third additional testicle dystopia is described.

Conclusion. Discovered multiple variants of blood vessel anomalies, peripheral nerves and internal genital organs in one individual are, apparently, evidence of various violations occurring in the embryonic period. The findings should be taken into account in cardiovascular, neurological and andrological practice.

Key words: anatomical variations, multiple anomalies, carotid artery, sublingual nerve, lateral cutaneous nerve of hip, additional testicle, dystopia.

\section{Введение}

В настоящее время проблема вариантной анатомии как одного из разделов нормальной анатомии человека сохраняет свою актуальность в связи с необходимостью расширения знаний об анатомии "усредненного человека» [7] с целью получения полных, статистически достоверных сведений о строении органов, их частей и организма в целом с учетом индивидуальных возрастных, половых, расово-этнических, эколого-географических особенностей в связи с функцией, развитием, воздействием на организм факторов окружающей среды на основе современных методических подходов - прижизненного скринингового исследования (компьютерной и магниторезонансной томографии, ультразвукового исследования, эндоскопии и др.), не исключая изучения трупного материала [5]. Вследствие несокращающегося в различных областях клинической медицины числа врачебных ошибок, обусловленных отсутствием полных сведений о многообразии вариантов и аномалий строения органов и приводящих к неблагоприятному исходу заболеваний в процессе проведения диагностических и лечебных мероприятий, особое внимание уделяется исследованию вариантной анатомии различных анатомо-физиологических систем. При этом необходимо различать варианты нормы и варианты аномалий [5]. Несмотря на то, что в литературных источниках накоплен достаточно большой материал по вариантной анатомии, периодические публикуемые данные о новых вариациях и аномалиях носят характер случайных находок. Именно этим можно объяснить имеющиеся в литературе противоре- 


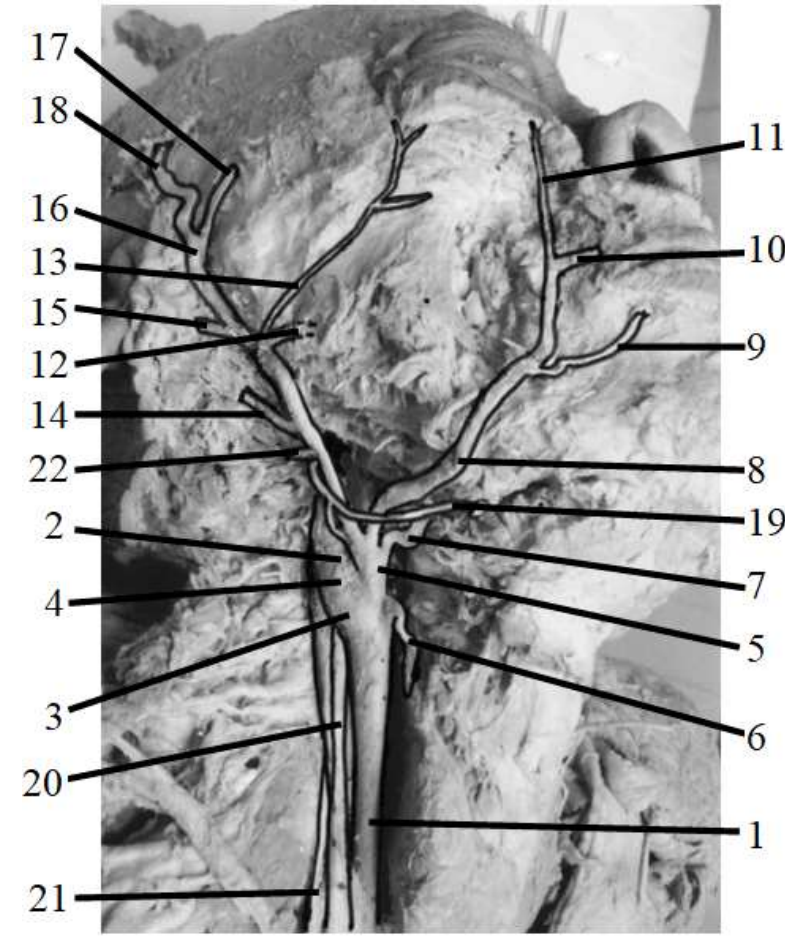

Pис. 1. Общий вид артерий и нервов головы и шеи (вид справа). Обозначения: 1 - общая правая сонная артерия, 2 - бифуркация общей сонной артерии, 3 - каротидный синус общей сонной артерии, 4 - внутренняя сонная артерия с «внутренним каротидным синусом», 5 - наружная сонная артерия с «наружным каротидным синусом», 6 - верхняя щитовидная артерия, 7 - язычная артерия, 8 - лицевая артерия, 9 - нижняя губная артерия, 10 - верхняя губная артерия, 11 - угловая артерия, 12 - верхнечелюстная артерия, 13 - поперечная артерия лица, 14 - затылочная артерия, 15 - задняя ушная артерия, 16 - поверхностная височная артерия, 17 - лобная ветвь, 18 - теменная ветвъ, 19 - подъязычный нерв, 20 - правый симпатический ствол, 21 - блуждающий нерв, 22 - грудиноключично-сосцевидная артерия.

чивые сведения о частоте выявления тех или иных анатомических вариантов и аномалий [5].

По распространенности аномалии делят на изолированные - с поражением одного органа; системные - с поражением нескольких органов одной из систем; множественные - с поражением органов разных систем [9].

\section{Материал и методы исследования}

Препарированию подвергся труп мужчины 52 лет, фиксированный 10\% раствором формалина. В процессе исследования проводились антропометрические измерения с использованием штангенциркуля. Обнаружены множественные аномалии в кровеносной, периферической нервной системах и в мочеполовом аппарате: билатеральная аномалия наружной сонной артерии и подъязычного нерва, билатеральная аномалия латерального кожного нерва бедра, поясничная эктопия добавочного третьего яичка. Из добавочного третьего яичка иссекали фрагмент ткани размером 0.5×0.5×0.5 cм, дополнительно фиксировали в 10\% растворе нейтрального формалина в течение суток, затем проводили по спиртам восходящей концентрации и заливали в парафин. Срезы толщиной 5 мкм окрашивали гематоксилином и эозином.

\section{Билатеральная аномалия наружной сонной артерии и подъязычного нерва}

Начало правой и левой общих сонных артерий, так же, как и их топография на шее до уровня обычного деления каждой из них на наружную и внутреннюю сонные артерии (верхний край щитовидного хряща или тело подъязычной кости), соответствовали типовым данным, описанным в специальной литеpaтуре (рис. 2: А - 3; Б - 4) [1, 3, 6, 8, 10].

На исследованном трупе обе общие сонные артерии аномально поднимались выше верхнего края щитовидного хряща, подъязычной кости до угла нижней челюсти, разделяясь несколько выше последнего на наружную и внутреннюю сонную артерии, в связи с чем для удобства препарирования углы нижней челюсти были удалены (рис. 1: 4, 5; рис. 2: $\mathrm{A}-7,8 ; \mathrm{5}-7,8)$. Диаметр левой общей сонной артерии у основания составлял $0.67 \mathrm{~cm}$, правой общей сонной артерии на том же уровне - 0.6 см. Длина общих сонных артерий от места начала до их бифуркации равнялась справа 9.8 см, слева - 13.5 см. Левая общая сонная артерия была на 0.7 см длиннее правой, что несколько больше, чем описано в литературных источниках. Перед бифуркацией общих сонных артерий находилось, как и в типичных случаях, утолщение - каротидный синус (рис. 1: 3; рис. 2: А - 6; Б - 6). Высота каротидного синуса составила справа $1.3 \mathrm{~cm}$, слева - 1.05 см; его ширина слева равнялась 1.55 см, справа - 1.6 см; толщина каротидного синуса достигала справа $1.0 \mathrm{~cm}$, слева $0.82 \mathrm{~cm}$.

В области каротидного синуса каждая из общих сонных артерий типично делилась на наружную (рис. 1:5; рис. $2:$ А - 7; Б - 7) и внутреннюю (рис. 1:4; рис. 2: А - 8; Б - 8) сонные артерии, начальные отделы которых утолщались, являясь как бы продолжением каротидного синуса общей сонной артерии, что позволило предположить о наличие «наружного» (рис. 1:5; рис. 2: А - 7; Б - 7) и «внутреннего» (рис. 1:4; рис. 2: А - 8; Б - 8) каротидных синусов. При этом «внутренний каротидный синус» отличался большими размерами, чем «наружный».

Известно, что от наружной сонной артерии отходят 3 группы артериальных ветвей: передняя, задняя и медиальная $[1,3,6,8,10]$. Передняя группа включает верхнюю щитовидную, язычную и лицевую артерии; 

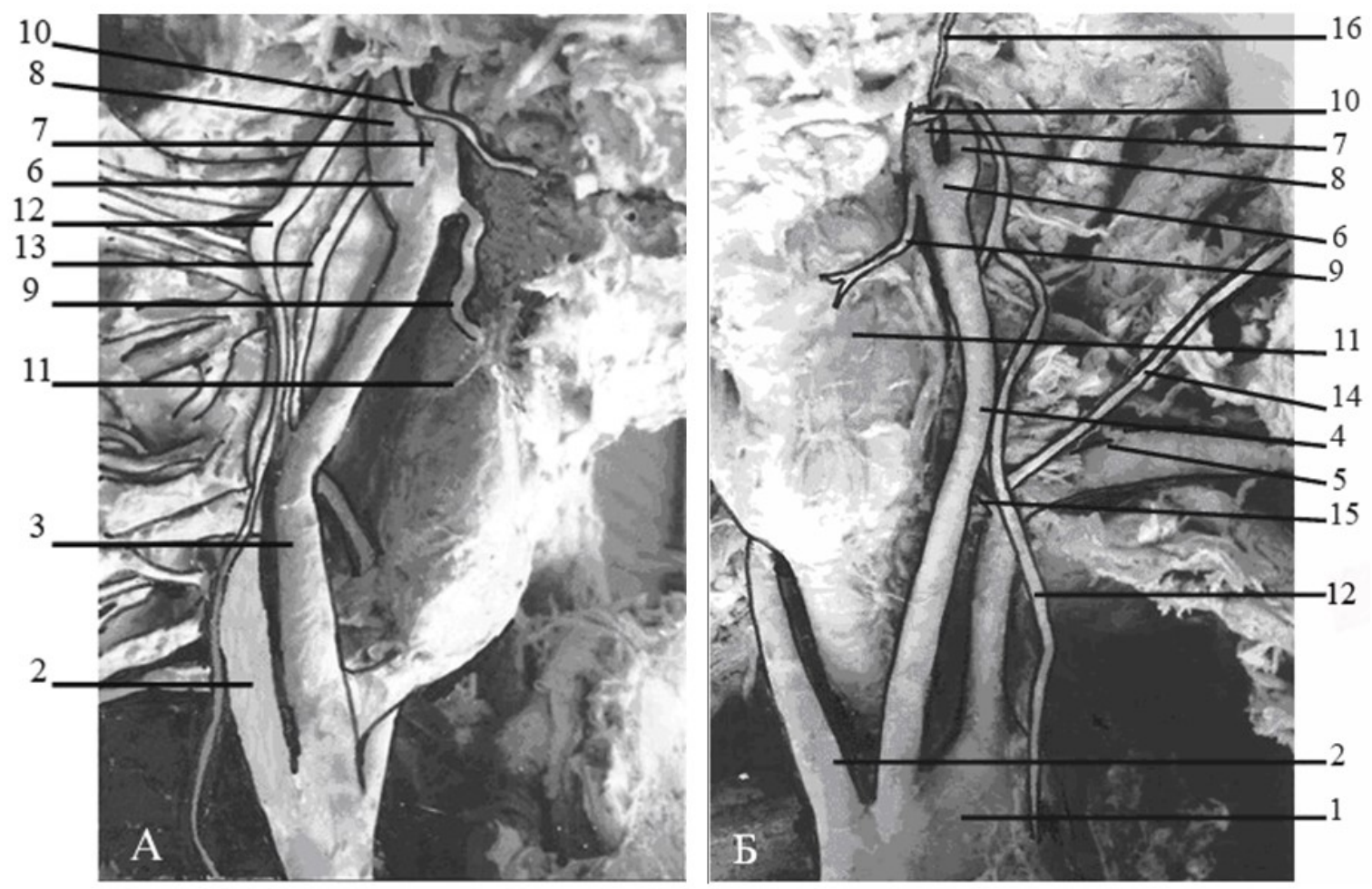

Рис. 2. Билатеральная аномалия артерий шеи. Обозначения: А - общий вид правой общей сонной артерии, вид спереди и справа; 5 - общий вид левой общей сонной артерии, вид спереди; 1 - дуга аорты, 2 - плечеголовной ствол, 3 - правая общая сонная артерия, 4- левая общая сонная артерия, 5 - левая подключичная артерия, 6 - каротидный синус общей сонной артерии, 7 - наружная сонная артерия с «наружным каротидным синусом», 8 - внутренняя сонная артерия с «внутренним каротидным синусом», 9 - верхняя щитовидная артерия, 10 - подъязычный нерв, 11 - щитовидная железа, 12 - блуждающий нерв, 13 - правый симпатический ствол, 14 - левая надлопаточная артерия, 15 - левая нижняя щиитовидная артерия, 16 - артериальная ветвь к околоушной железе
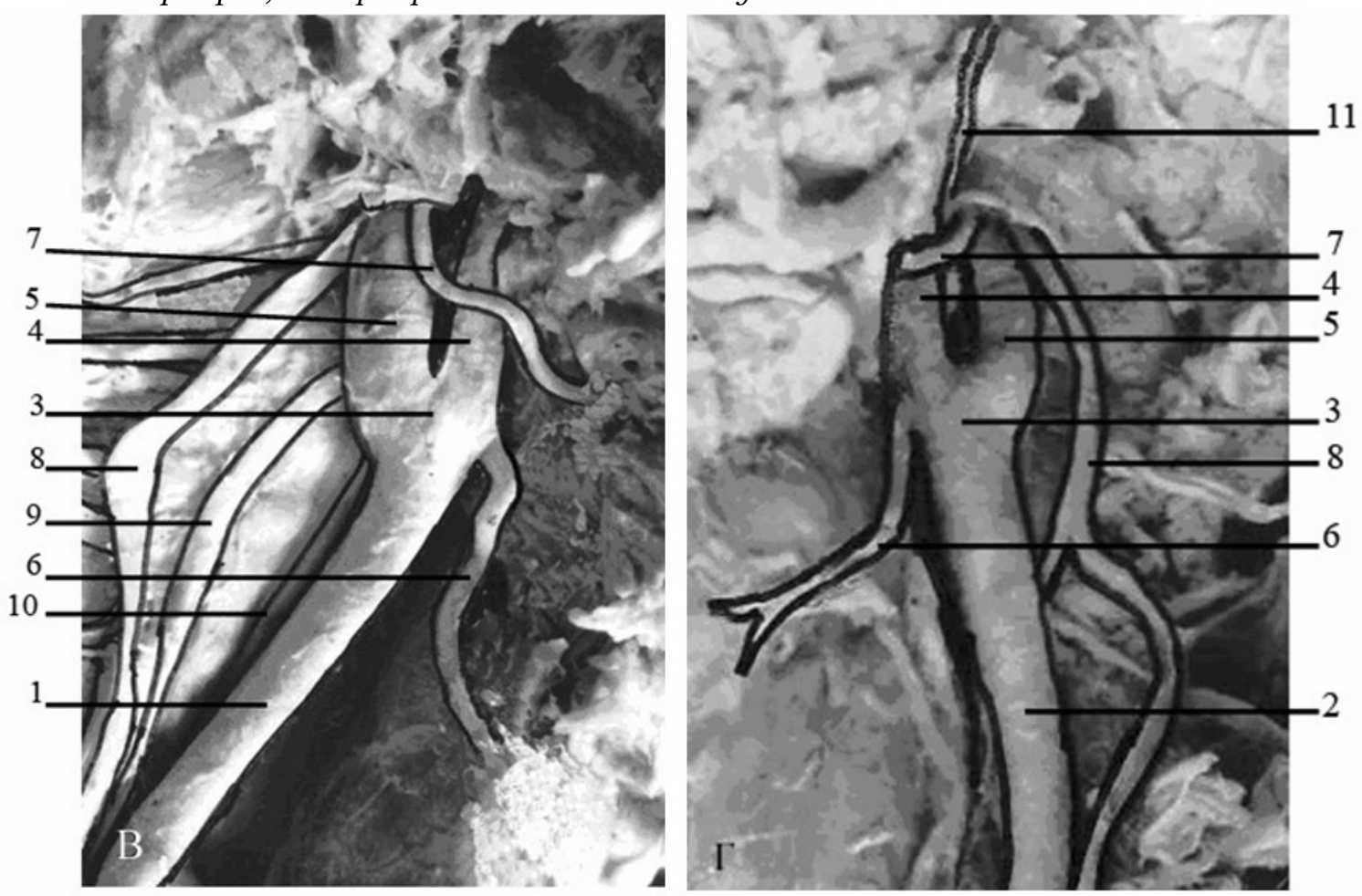

Рис. 3. Продолжение рис.2. В - фрагмент рис. 2, А; $Г$ - фрагмент рис. 2, Б. Обозначения: 1 - правая общая сонная артерия, 2 - левая общая сонная артерия, 3 - каротидный синус общей сонной артерии, 4- наружная сонная артерия с «наружным каротидным синусом», 5- внутренняя сонная артерия с «внутренним каротидным синусом», 6 - верхняя щитовидная артерия, 7 - подъязычный нерв, 8 - блуждающий нерв, 9 - правый симпатический ствол, 10 - нижний гортанный нерв, 11 - артериальная ветвь к околоушной железе 

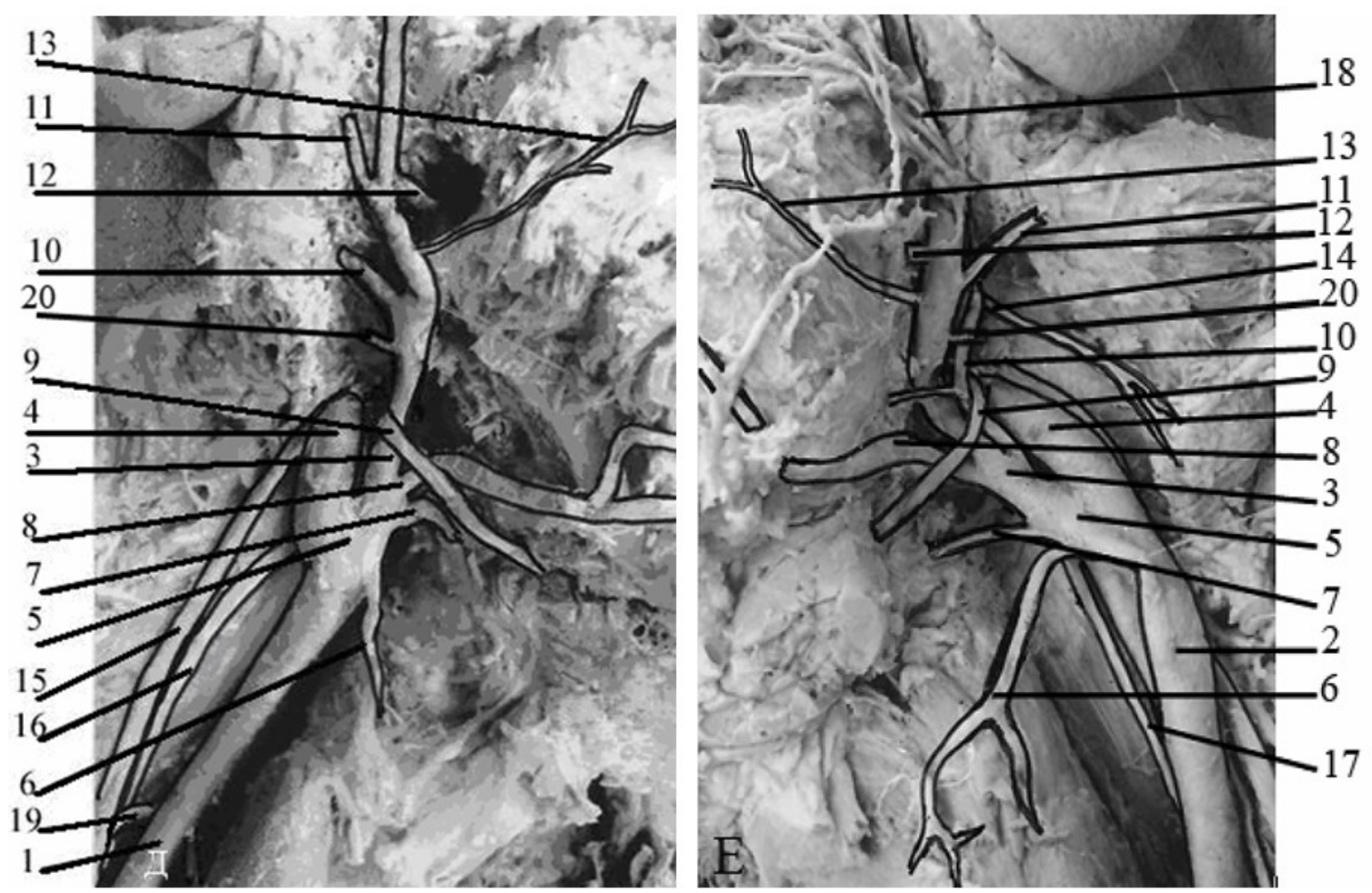

Рис. 4. Продолжение рис. 3. Д - фрагмент рис. 3, В; Е- фрагмент рис. 3, Г. Обозначения: 1 - правая общая сонная артерия, 2 - левая общая сонная артерия, 3 - наружная сонная артерия с «наружным каротидным синусом», 4- внутренняя сонная артерия с «внутренним каротидным синусом», 5 - каротидный синус общей сонной артерии, 6 - верхняя щитовидная артерия, 7-язычная артерия, 8 - лицевая артерия, 9 - подъязычный нерв, 10 - затылочная артерия, 11 - задняя ушная артерия, 12 - верхнечелюстная артерия, 13 - поперечная артерия лица, 14 - добавочный нерв, 15 - блуждающий нерв, 16 - правый симпатический ствол, 17 - левый симпатический ствол, 18 - ветви лицевого нерва, 19 - правая нижняя щзитовидная артерия, 20 - грудиноключично-сосцевидная артерия
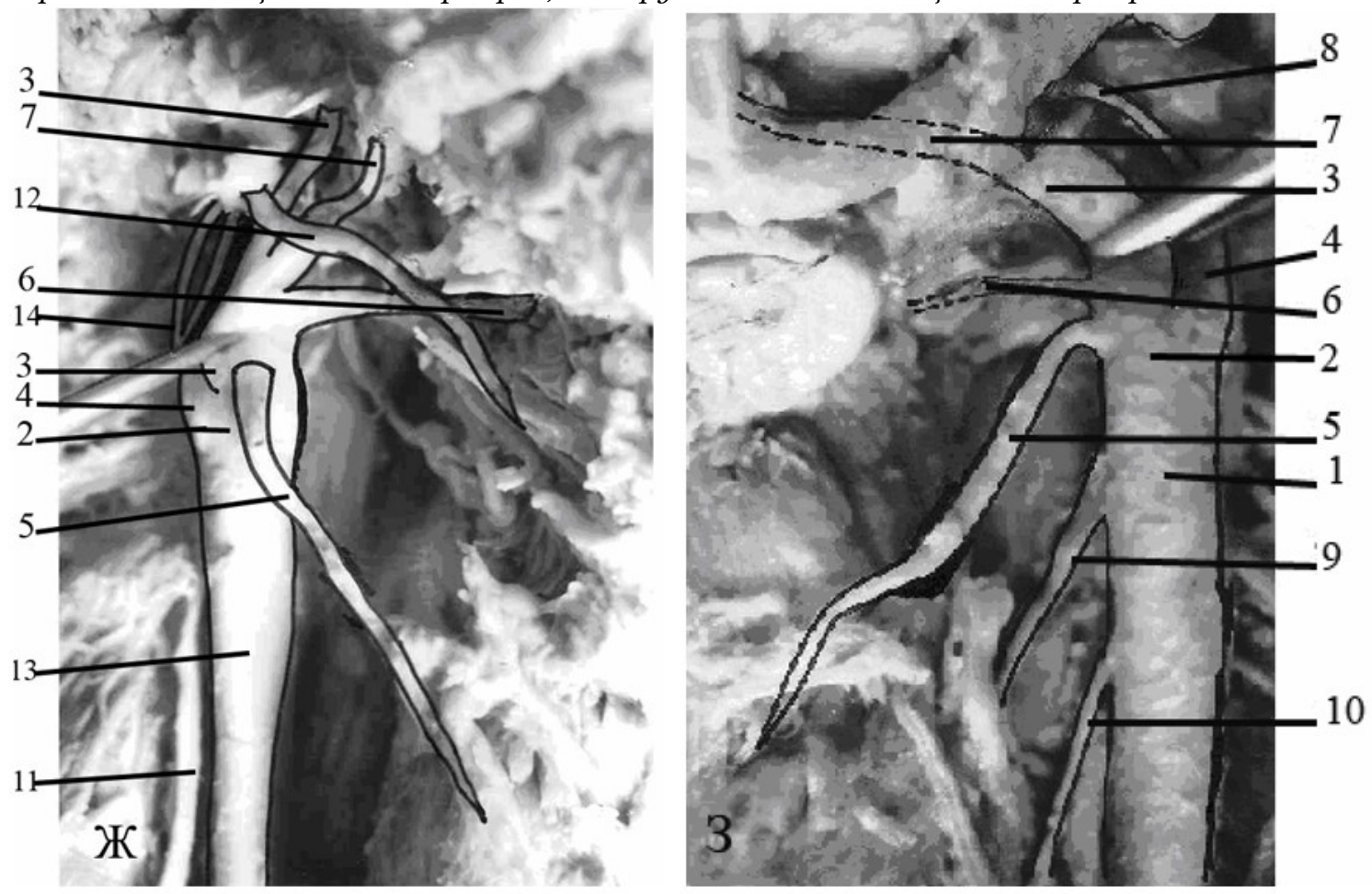

Рис. 5. Продолжение рис. 4, Ж - фрагмент рис. 4, Д; 3 - фрагмент рис. 4, Е. Обозначения: 1 - левая общая сонная артерия, 2 - каротидный синус общей сонной артерии, 3 - наружная сонная артерия (оттянута кнаружи) с «наружным каротидным синусом», 4- внутренняя сонная артерия с «внутренним каротидным синусом», 5- верхняя щитовидная артерия, 6 - язычная артерия, 7 - лицевая артерия, 8 - затылочная артерия, 9 - гортанная ветвь, 10 - трахеальная ветвь, 11 - диафрагмальный нерв, 12 - подъязычный нерв, 13 - правая общая сонная артерия, 14 - восходящая глоточная артерия 
задняя - затылочную, заднюю ушную и грудиноключично-сосцевидную артерии; медиальная - восходящую глоточную, поверхностную височную и верхнечелюстную артерии [1, $3,6,8,10]$.

Дистопия мест начала некоторых артерий наблюдались на исследованном трупе в каждой из выше названных групп ветвей наружной сонной артерии.

Среди ее передних ветвей атипично отходили следующие ветви.

Верхние щитовидные артерии начинались от внутренней поверхности каротидных синусов правой и левой общих сонных артерий, направлялись книзу и кнутри и разветвлялись соответственно в правой и левой долях щитовидной железы (рис. 2: А - 9; Б - 9; рис. 3: В - 6; Г-6);

Правые язычная и лицевая артерии отходили от внутренней поверхности «правого наружного каротидного синуса» на небольшом расстоянии друг от друга (рис. 1: 7, 8; рис. 4: Д - 7, 8);

Левая язычная артерия брала начало от левого «наружного каротидного синуса» и была атипично меньшего диаметра, чем одноименная правая, а левая лицевая артерия отходила от наружной сонной артерии на небольшом расстоянии от левой язычной артерии той же стороны (рис. 4: E - 7, 8).

Из ветвей задней группы наружной сонной артерии от нее кзади атипично отходила левая затылочная артерия на уровне места начала лицевой артерии той же стороны (рис. 4: E - 10). От затылочной артерии брала начало и направлялась кверху тонкая артериальная веточка к околоушной железе (рис. 2: Б - 16; рис. 3: Г - 11).

Из ветвей медиальной группы наружной сонной артерии атипично, от заднебоковой поверхности каротидного синуса правой и левой общих сонных артерий, начиналась восходящая глоточная артерия (рис. 5: Ж - 14) и поднималась кверху по задней поверхности глотки.

Кроме представленных выше сосудистых аномалий, от передней поверхности верхней трети общей сонной артерии атипично отходили две непарные артериальные ветви. Они направлялись книзу: одна - к гортани (рис. 5: 3 - 9), другая - к верхнему отделу трахеи (рис. 5, 3-10).

Морфогенез описанных аномалий общей сонной артерии и ветвей, обычно отходящих от наружной сонной артерии, особенно ее передней группы, вероятно, можно объяснить нарушением процессов внутриутробного развития артериальных дуг, остатки которых питают органы, возникающие из некоторых жаберных дуг и карманов.

Подъязычный нерв с обеих сторон аномально проходил по передне-медиальной поверхности внутренней сонной артерии, огибая спереди начальный отдел наружной сонной артерии и ее ветви: справа - наружную сонную, язычную и лицевую артерии (рис. 1: 19, 5, 7,8 ; рис. $4:$ Д - 9, 3, 8; рис. 5 : Ж - 12, 3, 6, 7), слева - затылочную, наружную сонную и лицевую артерии (рис. 4: $\mathrm{E}-9,3,8,10$ ).

Со стороны других ветвей правой и левой наружных сонных артерий и нервов головы и шеи аномалии отсутствовали.

В литературе описаны различные варианты и аномалии общей сонной артерии [13, 14, 17]. Ее деление на наружную и внутреннюю сонные артерии возможно выше подъязычной кости или на ее уровне; правые наружная и внутренняя сонные артерии могут отходить изолированно от плечеголовного ствола; иногда общая сонная артерия достигает наружного отверстия сонного канала и на протяжении отдает ветви, которые обычно берут начало от наружной сонной артерии. Иногда от внутренней сонной артерии отходит отделяющаяся обычно от наружной сонной артерии лицевая артерия. Кроме того, от общей сонной артерии могут отходить верхняя щитовидная, нижняя глоточная, позвоночная, нижняя щитовидная и одна гортанная артерии $[17,20,21]$.

Таким образом, описанные выше билатеральные аномалии общей сонной артерии и подъязычного нерва в доступной литературе нами не обнаружены, что необходимо учитывать при проведении оперативных вмешательств в области головы и шеи.

\section{Редкий вариант билатеральной аномалии латерального кожного нерва бедра}

В типичных случаях латеральный кожный нерв бедра выходит из-под наружного края большой поясничной мышцы, иногда прободая ее; следует, располагаясь под подвздошной фасцией, по передней поверхности подвздошной мышцы к передней верхней подвздошной ости и выходит на бедро медиальнее последней под латеральной частью паховой связкой в мышечной лакуне каудальнее глубокой артерии, огибающей подвздошную кость. Вскоре он прободает широкую фасцию бедра, затем разветвляется в коже на его наружной поверхности, доходя до коленного сустава. Его ветви могут образовывать соединения с передними кожными ветвями бедренного нерва [3, 8, 19].

В обнаруженной нами аномалии - дистопии правого и левого латеральных кожных нервов бедра - они, выходя из под большой поясничной мышцы вблизи ее наружного края, следовали каудально, присоединяясь на каждой стороне к бедренному нерву и сопровождая его в борозде между подвздошной и большой поясничной мышцами. Правый латеральный кожный нерв бедра проходил под паховой связкой (рис. 6: А - 3; Б - 3) в мы- 

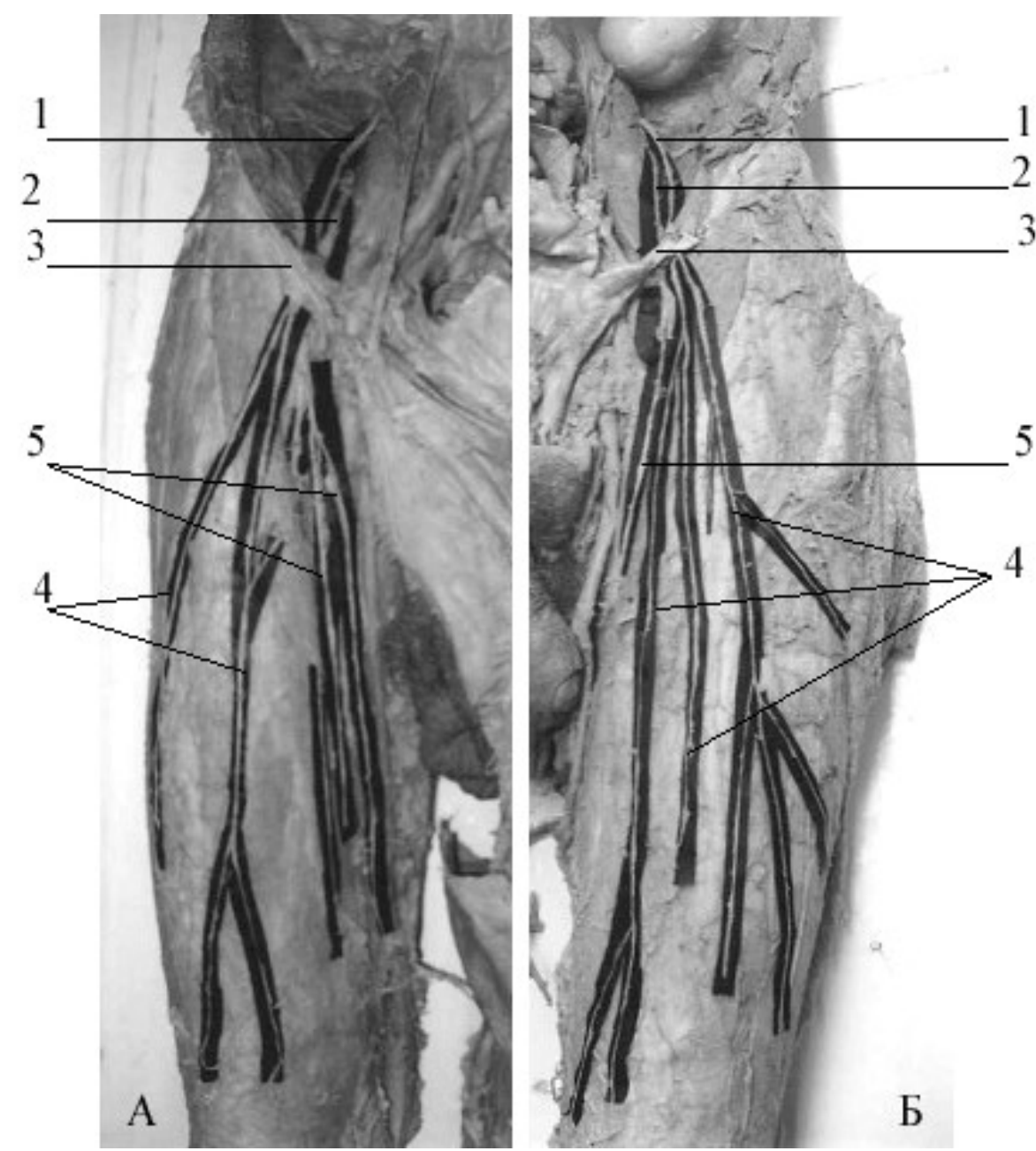

Рис. 6. Билатеральная аномалия наружного кожного нерва бедра. Обозначения: A - правая сторона; Б - левая сторона; 1 - наружный кожный нерв бедра; 2 - бедренный нерв; 3 - паховая связка; 4-ветви наружного кожного нерва бедра; 5 - передние кожные ветви бедренного нерва.

шечной лакуне на границе между ее средней и внутренней третями несколько латеральнее бедренного нерва (рис. 6: А - 1,2). Левый латеральный кожный нерв бедра выходил через мышечную лакуну так же несколько латеральнее бедренного нерва, но на уровне средней трети паховой связки (рис. 6: Б-1, 2). Ветви правого и левого латеральных кожных нервов бедра разветвлялись на переднелатеральной поверхности бедра, не доходя до коленного сустава (рис. 6: А - 4; Б - 4). По данным [15] латеральный кожный нерв бедра имеет вариантное расположение у $25 \%$ населения. Первое упоминание о его аномальном расположении датируются XIX в [19]. Описано его атипичное расположение относительно передней верхней подвздошной ости. В литературе не обнаружено сообщений о том, что наружный кожный нерв бедра с обеих сторон может проходить через мышечную лакуну на различном уровне паховой связки. Однако имеется единичное сообщение о том, что наружный кожный нерв бедра проходил с одной стороны через мышечную лакуну вместе с бедренным нервом, но не указывается на каком уровне паховой связки [12].

Описанный случай билатеральной аномалии наружного кожного нерва бедра необходимо учитывать при травмах в области передней поверхности верхней трети бедра, герниоэктомии и операциях в области подвздошной ямки.

\section{Редкая аномалия поясничной дистопии третьего яичка}

В случае с множественными аномалиями нами обнаружена поясничная дистопия третьего яичка. Оно располагалось в поясничной области, слева и на 5 см выше от бифуркации брюшной части аорты, на уровне III-IV поясничных позвонков, позади брюшины, на передней поверхности большой левой поясничной мышцы (рис. 7: 1). При этом верхний полюс яичка находился в области начала нижней брыжеечной артерии (рис. 7: 7) на уровне нижнего края III поясничного позвонка. Нижний конец яичка находился на уровне 


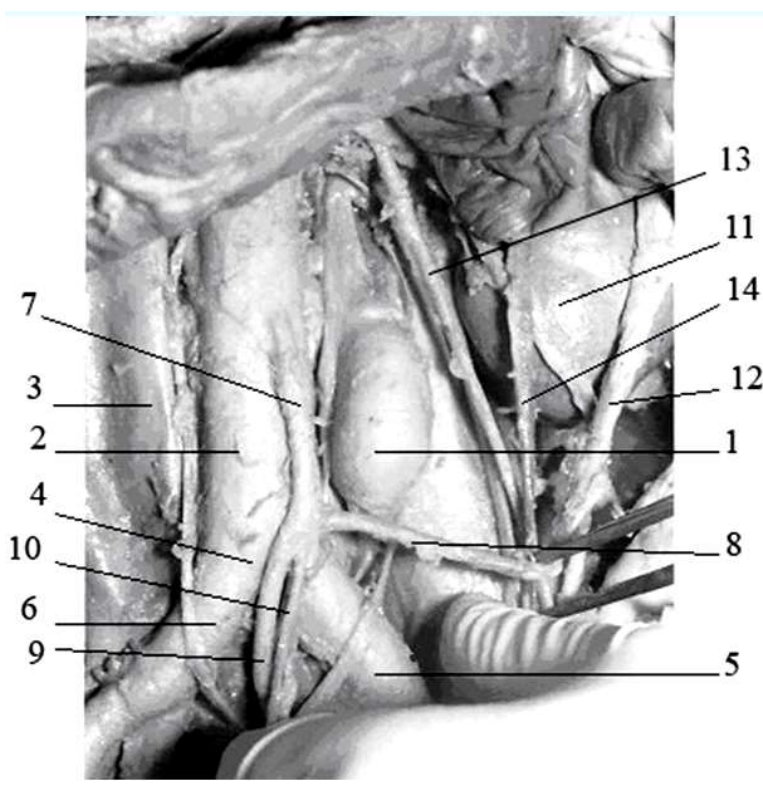

Рис. 7. Редкая аномалия поясничной дистопии третьего яичка. Обозначения: 1 - третье яичко, 2 - брюшная часть аорты, 3 - нижняя полая вена, 4 - бифуркация аорты, 5 - левая общая подвздошная артерия, 6 - правая общая подвздошная артерия, 7 - нижняя брыжеечная артерия, 8 - левая ободочная артерия, 9 - верхняя прямокишечная артерия, 10 - сигмовидная артерия, 11 - левая почка, 12 - левый мочеточник, 13 - левая яичковая артерия, 14 - левая яичковая вена.

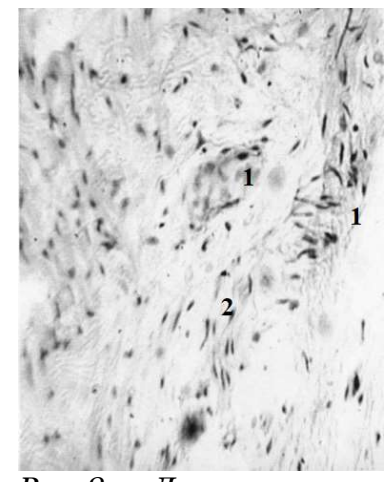

Рис. 8. Деструктивно измененные семенные канальцы в фиброзной строме добавочного третьего яичка. Обозначения: 1 - деструктивно измененные семенные канальцы; 2 - фиброзно измененная ткань добавочного третьего яичка; окраска гематоксилином и эозином; ок. 7, об. 90.

нижнего края IV поясничного позвонка, не доходя 1.0 см до бифуркации брюшной части аорты (рис. 7:4).

Длина яичка составила 3.58 см. Длина яичка с придатком достигала $4.76 \mathrm{~cm}$. Поперечный размер яичка в верхней, средней и нижней третях составил 1.2, 1.75 и 1.3 см соответственно. От придатка яичка кверху и медиально поднимался тяж длиной $3.3 \mathrm{~cm}$, который скрывался в большой поясничной мыш- це. Ширина тяжа на уровне его верхней, средней и нижней третей равнялась $0.5 ; 0.4$ и 0.3 см соответственно.

Размеры яичек, располагающихся в мошонке, были в пределах нормы.

При гистологическом исследовании среди элементов фиброзной ткани были обнаружены единичные деструктивно измененные семенные канальцы (рис. 8). В строме встречались одиночно расположенные клетки Лейдига (рис. 9), а также обнаруживались тонкостенные сосуды.

В доступной нам специальной анатомической и клинической медицинской литературе по поводу аномалии яичек имеются следующие данные [4, 11, 13, 15].

Недоразвитие яичек может достигать самой различной степени вплоть до полного отсутствия органа (анорхидия). Понятно, что яичко противоположной стороны в таких случаях оказывается более или менее увеличенным по сравнению с нормой (компенсаторная гипертрофия). Полное отсутствие яичек представляет редкое явление, причем эта аномалия обыкновенно совпадает с недоразвитием и других мочевых и половых органов (почек, мочеточников, придатка яичка, семявыносящего протока). Еще реже встречаются случаи появления третьего яичка -триорхидия. Добавочное (акцессорное) яичко, нередко недоразвитое, как правило, располагается вблизи нормального. Оно может иметь общий с ним придаток или иметь собственные придаток и семявыносящий проток, впадающий в основной семявыносящий проток на любом уровне его следования. В других случаях придаток нормального яичка оказывается общим с придатком аномального яичка, но снабжен двумя семявыносящими протоками. Подчас добавочное яичко не имеет ни придатка, ни протока и оказывается эмбриологически связанным с сосудистым руслом $[2,15]$.

В качестве аномалии встречается одно яичко, другое - не развивается. Такое отсутствие одного из двух яичек при одновременном отсутствии придатка и семявыносящего протока представляет собой монорхидию, которая встречается крайне редко [15]. Кроме этого, по данным анатомической литературы, наблюдается увеличение числа добавочных яичек (полиорхидия) в виде 3 (de Blaisins) - 1 случай, 4 (de Blegny) - 1 случай, 5 (Scharff) - 1 случай. Однако случаи с завершенным развитием представляют собой чрезмерный резерв сперматогенной и гормональной функций. При этом наблюдаются множественные внутренние изменения деталей строения. В некоторых описанных случаях эксцизионная микроскопия добавочных яичек соответствовала их характерной структуре. В то же время в отдельных случаях опухолевидное перерождение приводит к образованию округлых, близко расположенных сумок, харак- 
терных для аномальных или добавочных яичек, содержащих кисты, заполненные небольшим количеством жировой ткани [15].

Кроме вышеназванных, в публикациях упоминается о двух оригинальных наблюдениях триорхизма. Одно принадлежит Mariotti (1907), другое - L. Lerat (1910), каждый из которых обнаружил добавочное яичко. При обычном микроскопическом исследовании в одном из них наблюдалось характерное для яичка строение. В другом яичке на всем протяжении обнаружена атрофия, вследствие чего оно было нефункционирующим. В случае, описанном Mariotti, добавочное яичко напоминало опухоль и располагалось в левом паховом канале. В случае, представленном Lerat, добавочное яичко находилось в поверхностном кольце пахового канала. В одном из этих случаев существовал семявыносящий проток. Таким образом, триорхидия, как моноорхидия и анорхидия, встречаются чрезвычайно редко.

Таким образом, обнаруженное нами анатомическое образование представляет собой редкую аномалию - поясничную дистопию фиброзноизмененного третьего яичка с недоразвитым придатком, отсутствием семявыносящего протока и интрамуральными признаками тестикулярного строения: наличием единичных семенных канальцев с признаками деструкции, одиночно расположенными в строме клетками Лейдига и небольшим количеством кровеносных сосудов.

Поясничная эктопия добавочного яичка и особенности его внутреннего строения, очевидно, связаны с избыточным эмбриональным развитием зародышевого эпителия в месте закладки половой железы, нарушением дифференцировки ее тканей, задержкой опускания яичка и, как следствие, развитием фиброзной дегенерации стромы с атрофией канальцевой системы и потерей сперматогенной функции органа. Тем не менее сохранение клеток Лейдига и кровеносных сосудов не позволяет полностью исключить гормональную функцию пояснично дистопированного акцессорного яичка.

\section{Заключение}

Обнаруженные множественные варианты аномалий кровеносных сосудов, периферических нервов и внутренних половых органов у одного индивида являются, повидимому, свидетельством различных нарушений происходивших в эмбриональном периоде. Полученные данные необходимо учитывать в сердечно-сосудистой, неврологической и андрологической практике.

\section{Конфликт интересов}

Авторы заявляют об отсутствии конфликта интересов.

\section{Список литературы}

1. Анатомия человека : в 2 т., под ред. М.Р. Сапина. М.: Медицина; 1976; 2. 486.

2. Иванов Г. Ф. Основы нормальной анатомии человека: в 2 т. М.: Медгиз; 1949; 1.795.

3. Иванов Г. Ф. Основы нормальной анатомии человека: в 2 т. М.: Медгиз; 1949; 2. 384.

4. Лопаткина Н.А., Люлько А. В. Аномалии мочеполовой системы. Киев: Здоров'я; 1987. 416.

5. Петров А. В. и др. Некоторые общие и частные вопросы вариантной анатомии мышечной системы человека. Системный анализ и управление в биомедицинских системах. 2004;3 (3): 24-29.

6. Привес М.Г., Лысенков Н. К., Бушкович В. И. Анатомия человека: 10-е изд., перераб. и доп. СПб.: Гиппократ; 1997. 684 с.

7. Сапин M. Р. Сегодня и завтра морфологической науки. Морфология. 2000; 17(3): 6-8.

8. Синельников Р. Д. Атлас анатомии человека: в 3 т. М.: Медицина; 1981; 3.458.

9. Струков А.И., Серов В. В. Патологическая анатомия. М.: Медицина; 1979. 528.

10. Тонков B.H. Учебник нормальной анатомии человека. Л.: Медгиз; 1962. 764.

11. Юнда И. Ф. Болезни мужских половых органов: 2-е изд., перераб и доп. Киев: Здоров'я; 1989. 270.

12. Alverdes $K$. Grundlagen der Anatomie. VEB Georg Thieme; 1959; 2. Aufl. 841.

13. Berczi V., Bottomley J. R., Gopalan D. et al. Absent right common carotid artery with stenting of symptomatic internal carotid artery stenosis. J Vasc Surg. 2014 May;59(5):1418-21. doi: 10.1016/j.jvs.2012.11.138

14. Kim C. H., Cho Y.D., Kang H. S. et al. Anomalous External Carotid Artery-Internal Carotid Artery Anastomosis in Two Patients with Proximal Internal Carotid Arterial Remnants. Korean J Radiol. 2015 Jul-Aug;16(4):914-8. doi: 10.3348/kjr.2015.16.4.914

15. Palamar D., Terlemez R., Akgun K. UltrasoundGuided Diagnosis and Injection of the Lateral Femoral Cutaneous Nerve with an Anatomical Variation. Pain Pract. 2017 Nov;17(8):1105-1108. doi: 10.1111/papr.12559

16. Pauber-Kopsch. Lehrbuch und Atlas der Anatomie des Menschen: In 3. Bd. Georg Thieme - VerlagZeipzid; 1939. Bd. 2., 15. Aufl. 650.

17. Testut $L$. Traité d'anatomie humaine: septième édition revue, corrigée et augmentée. Paris; 1921; 2: 137 .

18. Testut L. Traité d'anatomie humaine: septième édition revue, corrigée et augmentée. Paris; 1921; 4: 230-231.

19. Tomaszewski K.A., Popieluszko P., Henry B. M. et al. The surgical anatomy of the lateral femoral cutaneous nerve in the inguinal region: a meta-analysis Hernia. 2016 Oct;20(5):649-57. doi: 10.1007/s10029-016-14937

20. Troupis T., Michalinos A., Dimovelis I. et al. Bilateral abnormal origin of the anterior branches of the external carotid artery. Ann Vasc Surg. 2014 Feb;28(2):494.e5-7. 10.1016/j.avsg.2013.04.020

21. Uchino A., Saito N., Watadani T. Congenital external carotid-internal carotid artery anastomosis diagnosed by MR angiography. J Neuroimag- 
ing. 2013 Jan;23(1):96-7. doi: 10.1111/j.15526569.2011.00613.x

\section{References}

1. Anatomiya cheloveka [Human anatomy] : v 2 t., pod red. M.R. Sapina. M.: Meditsina; 1976; 2. 486 (in Russian).

2. Ivanov G. F. Osnovy normal'noy anatomii cheloveka [Basis in human anatomy]: v 2 t. M.: Medgiz; 1949; 1. 795 (in Russian).

3. Ivanov G. F. Osnovy normal'noy anatomii cheloveka [Basis in human anatomy]: v 2 t. M.: Medgiz; 1949; 2. 384 (in Russian).

4. Lopatkina N. A., Lyul'ko A. V. Anomalii mochepolovoy sistemy [Anomalies of the urogenital system]. Kiev: Zdorov'ya; 1987. 416 (in Russian).

5. Petrov A. V. i dr. Nekotorye obshchie i chastnye voprosy variantnoy anatomii myshechnoy sistemy cheloveka [Some general and particular questions of the variant anatomy of the human muscular system]. Sistemnyy analiz i upravlenie v biomeditsinskikh sistemakh. 2004;3 (3): 24-29 (in Russian).

6. Prives M. G., Lysenkov N. K., Bushkovich V. I. Anatomiya cheloveka [Human anatomy]: 10-e izd., pererab. i dop. SPb.: Gip-pokrat; 1997. 684 (in Russian).

7. Sapin M. R. Segodnya i zavtra morfologicheskoy nauki [Today and tomorrow of morphological science]. Morfologiya. 2000; 17(3): 6-8 (in Russian).

8. Sinel'nikov R. D. Atlas anatomii cheloveka $[\mathrm{Hu}-$ man anatomy atlas]: v 3 t. M.: Meditsina; 1981; 3. 458 (in Russian).

9. Strukov A. I., Serov V. V. Patologicheskaya anatomiya [Pathological anatomy]. M.: Meditsina; 1979. 528 (in Russian).

10. Tonkov V. N. Uchebnik normal'noy anatomii cheloveka [Human anatomy]. L.: Medgiz; 1962. 764 (in Russian).

11. Yunda I. F. Bolezni muzhskikh polovykh organov [Diseases of male genital organs]: 2-e izd., pererab i dop. Kiev: Zdorov'ya; 1989. 270 (in Russian).

12. Alverdes K. Grundlagen der Anatomie. VEB Georg Thieme; 1959; 2. Aufl. 841.

13. Berczi V., Bottomley J. R., Gopalan D. et al. Absent right common carotid artery with stenting of symptomatic internal carotid artery stenosis. J Vasc Surg. 2014 May;59(5):1418-21. doi: 10.1016/j.jvs.2012.11.138
14. Kim C. H., Cho Y. D., Kang H.S. et al. Anomalous External Carotid Artery-Internal Carotid Artery Anastomosis in Two Patients with Proximal Internal Carotid Arterial Remnants. Korean J Radiol. 2015 Jul-Aug;16(4):914-8. doi: 10.3348/kjr.2015.16.4.914

15. Palamar D., Terlemez R., Akgun K. UltrasoundGuided Diagnosis and Injection of the Lateral Femoral Cutaneous Nerve with an Anatomical Variation. Pain Pract. 2017 Nov;17(8):1105-1108. doi: 10.1111/papr.12559

16. Pauber-Kopsch. Lehrbuch und Atlas der Anatomie des Menschen: In 3. Bd. Georg Thieme - VerlagZeipzid; 1939. Bd. 2., 15. Aufl. 650.

17. Testut L. Traité d'anatomie humaine: septième édition revue, corrigée et augmentée. Paris; 1921; 2: 137 .

18. Testut L. Traité d'anatomie humaine: septième édition revue, corrigée et augmentée. Paris; 1921; 4: 230-231.

19. Tomaszewski K.A., Popieluszko P., Henry B. M. et al. The surgical anatomy of the lateral femoral cutaneous nerve in the inguinal region: a meta-analysis Hernia. 2016 Oct;20(5):649-57. doi: 10.1007/s10029-016-14937

20. Troupis T., Michalinos A., Dimovelis I. et al. Bilateral abnormal origin of the anterior branches of the external carotid artery. Ann Vasc Surg. 2014 Feb;28(2):494.e5-7. 10.1016/j.avsg.2013.04.020

21. Uchino A., Saito N., Watadani T. Congenital external carotid-internal carotid artery anastomosis diagnosed by MR angiography. J Neuroimaging. 2013 Jan;23(1):96-7. doi: 10.1111/j.15526569.2011.00613.x

\section{Сведения об авторах}

Кварацхелия Анна Гуладиевна - канд. биол. наук, доцент кафедры нормальной анатомии человека ФГБОУ ВО «Воронежский государственный медицинский университет им. Н.Н. Бурденко» Минздрава России. 394036, г. Воронеж, ул. Студенческая, 10. E-mail: anna_kvar_83@mail.ru

Соколов Дмитрий Александрович - канд. мед. наук, доцент кафедры нормальной анатомии человека ФГБОУ ВО «Воронежский государственный медицинский университет им. Н.Н. Бурденко» Минздрава России. 394036, г. Воронеж, ул. Студенческая, 10.

Поступила в редакцию 12.12.2017 г.

Для ц̧итирования: Кварацхелия А.Г., Соколов Д.А. Редкий случай множественных аномалий. Журнал анатомии и гистопатологии. 2018; 7(1): 53-61. doi: 10.18499/2225-7357-2018-7-1-53-61

For citation: Kvaratskheliya A.G., Sokolov D.A. A rare case of multiple anomalies. Journal of Anatomy and Histopathology. 2018; 7(1): 53-61. doi: 10.18499/2225-7357-2018-7-1-53-61 